Article

\title{
The Characteristics of Locally Led Development in the Pacific
}

\author{
Chris Roche ${ }^{1, *}$, John $\operatorname{Cox}^{1}$, Mereani Rokotuibau ${ }^{2}$, Peni Tawake ${ }^{3}$ and Yeshe Smith ${ }^{1}$ \\ ${ }^{1}$ Institute for Human Security and Social Change, La Trobe University, Melbourne, 3086, Australia; \\ E-Mails: c.roche@latrobe.edu.au (C.R.), j.cox2@latrobe.edu.au (J.C.), y.smith@latrobe.edu.au (Y.S.) \\ 2 Balance of Power Program, Pacific Women Shaping Pacific Development, 19419 Suva, Fiji; \\ E-Mail: mereani.rokotuibau@bop.org.fj \\ ${ }^{3}$ Australia Pacific Training Coalition, 14319 Suva, Fiji; E-Mail: peni.tawake@aptc.edu.au \\ * Corresponding author
}

Submitted: 7 August 2020 | Accepted: 13 October 2020 | Published: 25 November 2020

\begin{abstract}
There is a growing recognition of the effectiveness of locally led processes of social change and development. However, most of the case studies that have been discussed in the literature are focused on programs run by international development agencies. This article examines three locally led processes of change in the Pacific. These include the Simbo for Change Initiative in the Solomon Islands, the Voice in Papua New Guinea and a regional process led by the Green Growth Coalition. We explore how local understandings of leadership, preferences for informal ways of working, holistic ways of thinking, the importance placed upon maintaining good relationships and collective deliberation fundamentally shaped each of the cases. We note how these preferences and ways of working are often seen, or felt, to be at odds with western modes of thought and the practice of development agencies. Finally, we conclude by exploring how these initiatives were supported by external agencies, and suggest further research of this type might provide benchmarks by which Pacific citizens can hold their governments and development agencies to account.
\end{abstract}

\section{Keywords}

coalitions; development; developmental leadership; livelihoods; local development; Pacific; politics

\section{Issue}

This article is part of the issue "Leadership and Political Change in Asia-Pacific" edited by David Hudson (University of Birmingham, UK), Nicolas Lemay-Hébert (Australian National University, Australia), Claire Mcloughlin (University of Birmingham, UK) and Chris Roche (La Trobe University, Australia).

(C) 2020 by the authors; licensee Cogitatio (Lisbon, Portugal). This article is licensed under a Creative Commons Attribution 4.0 International License (CC BY).

\section{Introduction}

There is a growing promotion of locally led processes of social change and development. However, most of the case studies that have been developed and discussed in the literature and the international development arena are generally focused on programs run by international development agencies, for example the Coalitions for Change program in the Philippines (Sidel \& Faustino, 2020), the State Accountability and Voice Initiative in Nigeria (Booth \& Chambers, 2014), Pyoe Pin in Myanmar (Christie \& Green, 2018), or the Vanuatu Skills program (Barbara, 2019). This article, by contrast, examines three locally led processes of change in the Pacific (as opposed to projects), and seeks to understand their specific nature.

As a number of authors have noted, the concept of 'the local' is contested and often unhelpfully "constructed in binary opposition to the international" (Roepstorff, 2020 , p. 285). Further, the local "has been depicted as the problem and the solution" (Mac Ginty, 2015, p. 847): Something, or somewhere, either to be civilised or developed, or romanticised as the "potential saviour" of the deficiencies of international efforts to promote development (Mac Ginty, 2015, p. 841). Such conceptualisations of localisation by international actors, it is 
argued, run the risk of reproducing existing power relations (Roepstorff, 2020, p. 292), through new forms of "remote control" (van Voorst, 2019, p. 2117). There is therefore a call for a more 'critical localism' that not only avoids oppositions between local and international dimensions, but that explores vernacular understandings of the local, the agency of different actors and the complex webs of power in which they are located (Mac Ginty, 2015; Roepstorff, 2020). This article attempts to do this through an examination of three specific cases that can be described as locally led in the sense that they are "driven by a group of local actors who are committed to a reform agenda and would pursue it regardless of external support" (McCulloch \& Piron, 2019, p. 8), and "who are local in the sense of not being mere implementers of a donor agenda" (Booth \& Unsworth, 2014, p. 1).

Critical development literature has highlighted the problems with traditional top-down development institutions and the power inequities and failures associated with modernist and neoliberal modes of development practice. Much of this literature is aligned with postdevelopment theories and anticipates the emergence of new practices that can continue to strive towards greater global equity without reproducing neocolonial tendencies of the past (Escobar, 2018; Klein \& Morreo, 2019). Escobar in particular notes the importance of what he calls "autonomous design" as part of this practice. That is practice that is both based on a given community's understanding of its own realities and that seeks to change norms from within: "It might involve the defense of some practices, the transformation of others, and the veritable invention of new practice" (Escobar, 2018, p. 172). This inevitably leads to a plural and emergent understanding of what constitutes development or indeed postdevelopment. We use this lens to explore the three case studies presented in the article. As such we are not seeking to evaluate the 'development effectiveness' of these initiatives according to some predefined criteria, rather we are seeking to investigate how the concepts of critical localism and critical development might help illuminate specific cases of local, communal and relatively 'autonomous design.'

\section{Case Study Selection and Methodology}

In order to expand the horizons of 'the local,' the cases explored in this article have been chosen to represent locally led initiatives that engage in different but intersecting "scale-making projects" (Tsing, 2000, 2005). These include: the Simbo for Change movement on the apparently classically small and bounded local scale of the island of Simbo in Solomon Islands (in fact Simbo for Change relied on both mobilising local identity and creating connections with national and international bodies); The Voice Inc., a national level youth initiative in Papua New Guinea; and the Green Growth Leaders' Coalition, a Pacific regional process seeking to promote 'green growth.' These disparate case studies have been select- ed, not as representative examples of local, national and regional scales, but as lenses through which to understand the dynamics of scale in the Pacific, both as the "enduring realities of scale and distance" that shape Pacific states (Allen \& Dinnen, 2015, p. 381), and as contingent investments in scale-making projects that create and redefine the local in different contexts.

These cases have been the subject of ongoing mixed methods action research (key informant interviews, surveys, community focus groups and participant observation) by academics and consultants from La Trobe University's Institute for Human Security and Social Change. In the cases of Simbo for Change and the Green Growth Leaders' Coalition, the action research was initiated under the Australian aid program's Pacific Leadership Program (PLP) and the major findings and the specifics of data collection have already been reported elsewhere (Craney \& Hudson, 2020; Denney \& McLaren, 2016; Suti, Hoatson, Tafunai, \& Cox, 2020). The Voice Inc. case study has emerged from other action research in Papua New Guinea that the Institute has an ongoing role in, and has been developed in close collaboration with key actors from the Voice.

The Institute's approach to researching contemporary development practice has evolved into a collaborative model that decentres academic researchers from the research process and engages development practitioners as co-creators of knowledge. We are influenced by postcolonial Pacific models of reflexive learning such as the talanoa (Vaioleti, 2006) and tok stori models (Sanga \& Reynolds, 2018) that create space for mutual listening and reflection between multiple research participants as peers.

Our action research approach has evolved into an informal network of academics and development practitioners from Australia and the Pacific (many of whom have been involved in PLP) who meet to reflect on contemporary development discourse and practice in the Pacific, particularly the politics of knowledge production. This process has included several face to face meetings and a conference session held at the Research for Development Impact conference on "Leadership for Inclusive Development" held at La Trobe University in June 2019. This group has selected the three case studies discussed in this article as examples of Pacific led development that demonstrate important principles of local agency at different scales.

\subsection{Simbo for Change}

Simbo is a small island of some 1,800 people in the Western Province of Solomon Islands. The majority of the population are members of the Methodist or Seventh Day Adventist churches. Simbo for Change is an initiative begun in 2012 by Esther Suti, a business woman from the island (Suti et al., 2020, p. 3). Esther, who at the time was based in Gizo, the provincial capital, had noticed that women who travelled from Simbo to sell agricultural pro- 
duce in the market were often subject to violence and harassment. Furthermore, the trip to Gizo often involved an overnight stay and raised concerns about child-care and protection back on the island (Suti et al., 2020, p. 8). Esther sought to assist her fellow islanders in addressing these issues, not least by exploring how alternative livelihood options might reduce travel demands and promote family safety.

Rather fortuitously, after having failed to find support for her ideas in the Solomon Islands, Esther was introduced to the NGO Samoan Women in Business Development Inc (SWIBDI). SWIBDI's approach to women's empowerment and sustainable agriculture aligned well with Esther's interests and she struck up an important personal friendship with Adimaimalaga Tafunai (hereafter Adi), the CEO (Suti et al., 2020, p. 9). Adi's connection with an Australian government funded development program - the PLP-enabled Esther and SWIBDI to find the financing necessary to collaborate. PLP resourcing allowed SWIBDI staff to travel to Simbo and provide technical support to agricultural livelihoods initiatives, in ways that would reduce the need to travel away from the island (Denney \& McLaren, 2016, p. 9). This included experimenting with virgin coconut oil and the production of coconut soap, as well as reviving honey production.

Not all of these livelihood projects were successful. The coconut oil and soap production did not progress as hoped, but income from honey has been substantial. Some 300 hives are now reported to be in use, with income projected to be more than SBD $\$ 500,00$ per annum (US $\$ 61,200$ ) and being used to pay school fees and home infrastructure (International Fund for Agricultural Development, 2018). This has contributed to 'Simbo Honey' gaining a national reputation and Solomon's honeybees more generally being seen as a viable source of income (Akwai, 2019).

In July 2017, the partnership between Esther and SWIBDI also led to Simbo becoming the first internationally accredited organic island in Solomon Islands. SWIBDI had a long-standing interest in organic agriculture and recognised the possibility for Simbo to also pursue this path given its low use of pesticides, fertilizers and other inputs. This led to SWIBDI providing support for a successful plan to achieve certification, including training on composting and manuring, and further restricting the use of insecticides, animal drugs or antibiotics. These activities, combined with women's savings clubs formed by the women's group Madegugusu Women's Association, were undertaken on an island-wide basis. Indeed, Esther, in part due to exchanges with PLP staff, became insistent that this all-encompassing approach should be the case despite SWIBDI suggesting that a more focused experimental trial and error approach might be a better starting point.

Ensuring that all four tribes on the island, and the chiefs of those tribes, were engaged was a politically shrewd way of mobilising the island scale as a collective identity that respected the place of existing leaders while allowing space for new activities and leadership roles among women. This positioned Simbo as a model community to the provincial and national governments (Suti et al., 2020, p. 8).

The relationship between SWIBDI and Simbo was also underpinned by a much longer historical connection between the Island and Samoa. Samoan Methodist missionaries are reported to have brought Christianity to Simbo in the early 1900s (Dureau, 2001). This "second coming" of Samoans to Simbo, as some on the island called it, seems to have enabled deep levels of trust built on shared moral purpose and Christian values (Suti et al., 2020, p. 9).

As a locally led initiative, Simbo for Change focused on reinvigorating the island scale, using a mix of livelihoods development, and work that cemented social cohesion using appeals to Christianity and traditional leadership. Yet, far from being a conservative social movement, Simbo for Change has been able to address gendered inequity, as have other small initiatives in the Western Solomons (Cox, 2017; McDougall, 2014). Simbo for Change has done so by stretching the 'local' beyond the island scale and reimagining the island as reconnected to and held in esteem by provincial, national and Pacific regional actors.

In Escobar's terms, this case illustrates an emergent process of 'autonomous design': Simbo for Change was locally led but supported by a broader network of actors beyond the island. Interestingly, a previous study of the response to the 12-metre tsunami which struck Simbo and neighbouring islands in 2007 had pointed to similar processes (Lauer et al., 2013). Lauer et al. (2013, p. 48) found that strong social capital and resilience on the island was bolstered by an "intermeshing with largerscale processes" that enabled islanders to gain experience and qualifications off the island and was then used to help provide the necessary leadership to respond effectively to the crisis.

\subsection{The Voice Inc.}

The Voice Inc. (TVI) is a Papua New Guinean youth organisation which was established in 2007 by a group of law students at the University of Papua New Guinea. Initially, they sought to provide legal education to people living in Port Moresby's informal settlements, and, in 2009, launched the Clean Generation campaign. This anti-corruption initiative launched on World Clean Up Day attracted some 200 young people to remove rubbish in Port Moresby: a metaphor for a new generation of educated young leaders prepared to clean up the physical environment and the corruption that is seen to characterise the political order (Walton, 2018). Since then, the Clean Generation campaign has mobilised thousands of participants, and supports a radio program, a magazine (published in both English and Tok Pisin) and a substantial social media presence. TVI has also expanded its activities to other universities in Papua New Guinea (notably 
the University of Technology in Lae, and the University of Goroka) and developed a youth leadership development program (DREAM). This program works on personal development and now has two additional levels: "Active Citizens" and "Nation Builders," designed to build not just individual but collective leadership skills. Over time, TVI has grown from being an organic movement based around some core friendships into a formal NGO which incorporated in 2010.

TVI's day to day culture is characterised by the prominence of female leadership. Most of the TVI staff are women and the organisational culture is notable for the way that young men adapt to this environment respectfully. Whilst some might regard TVI as a relatively privileged group of middle-class students, the importance of modelling alternative gender norms in Papua New Guinea cannot be underestimated. TVI is an explicitly Christian organisation but unlike conventional churches has been successful in creating spaces where young people feel accepted without being subject to an organisational hierarchy. Many TVI members do not attend church regularly but do find their faith validated through the DREAM and other TVI activities.

Many students subsequently take up leadership roles in community groups or campaigns. This aligns with TVI's aims for collective leadership that can address challenges that Papua New Guinea faces at a national scale, primarily by imagining TVI members and alumni as attaining positions of influence as ethical actors who can reshape the nation. TVI has close links with anticorruption groups such as Transparency International Papua New Guinea, has fed into legislative reform undertaken by the Constitutional Law Reform Commission, and has strong relationships with the National Youth Development Authority. TVI's institutional partnerships are increasingly populated by TVI alumni, whose career paths have benefited from the informal networks fostered by TVI activities. TVI are exploring how this growing network might be the basis of broader reform coalitions, for example in the area of youth drug and alcohol issues.

TVI enjoys a high public profile and has been successful in attracting support from international agencies such as: the German NGO, Bread for the World, who provide core funding; Oaktree, an Australian youth NGO; Oxfam; and the Australian Aid program. Their partnerships also include large corporations in the resources sector, such as Oil Search and Exxon-Mobil. The corporate partnerships provide mentoring (particularly in science, technology, engineering and mathematics) for young women leaders by Papua New Guinean women who work in these organisations. TVI note that corporate partners have much less demanding reporting requirements than NGOs or aid donors and are much easier to work with, a point that traditional donors have cause to reflect on.

In 2016 student unrest broke out on university campuses protesting against corruption and demanding the then Prime Minister Peter O'Neill stand aside. As the protests became more politicised, students fragmented into provincial or tribal groups affiliated to competing camps of politicians. These protests became volatile with police firing on the University of Papua New Guinea students, with one student being killed and campus buildings being destroyed. This led to some deep reflection by TVI who noted how readily students mobilised around sub-national identities rather than the principled commitment to the national interest that TVI tried to foster. This stock-taking led to TVI rethinking how it might support collective action and coalition building, and how it might leverage and support its extensive alumni network. In the wake of the protests, Student Representative Councils were dissolved as trust between students and university administrators declined. University officials, who have generally been supportive of TVI, see that this provides the organisation with a new legitimacy. At the same time, TVI seeks greater financial sustainability without becoming dependent on any one donor, aiming to raise $40 \%$ of its own funds through fee-for-service income such as a recent youth survey that they conducted in Southern Highlands for Oil Search.

None of this is easy. Acting as a mediating organisation between students and university administrators can be seen as politically quietist. Association with extractive industries may pose a risk to TVI's reputation. An organisation that seeks to build coalitions, and indeed build bigger alliances who can bundle different interests, may be subject to accusations of co-optation. At the same time, TVI is an interesting example of how young women leaders have navigated various public domains-normally dominated by older men-and created accessible public space for themselves. Further, they have done this at the same time as seeking to preserve their vision and values, and while managing the complex and divergent expectations of their funding partners. Sometimes this means that they have rejected external funding that they feel undermines TVI's ability to act flexibly and responsively.

The case of TVI demonstrates an approach grounded in a belief in the importance of mobilising collective action and leadership, based in large part on identity, in this case 'youth' reconfigured as a "Clean Generation" of nascent national leaders. But it also illustrates how other identities i.e., regional and sub-national identities, and gender can intersect with, complicate or undermine such processes, and the compromises that may be needed to build broader alliances.

\subsection{The Green Growth Leaders' Coalition}

The Green Growth Leaders' Coalition (GGLC), established in 2012 , is a regional coalition which works under the umbrella of the International Union for Conservation of Nature Oceania (IUCN). This coalition was built upon a long-standing network of individuals who question externally driven approaches to development in the region, and how Pacific leaders have responded to that imposition (Craney \& Hudson, 2020, p. 4). The coalition is made up of current and former national politicians, as well 
as leaders from regional organisations, the private sector, churches and civil society. The membership is fluid and informal, with selection based on "leadership experience and ability to effect change within their communities and countries within the next five years" (IUCN, 2016). GGLC is usually described as "a fellowship of likeminded individuals" (Craney, 2020, p. X) rather than a formal grouping. Its purpose has been to promote 'green growth' in the region by creating spaces for leaders in the region to share experiences and learn from each other and develop strategies and policies for change (Craney \& Hudson, 2020, p. 5). Like the Simbo for Change initiative, it was supported until 2017 by the Australian government-funded PLP.

Aidan Craney (2020) describes GGLC's informal ways of working and its elite status. Here we describe some of GGLC's achievements. Whilst these are hard to definitively measure, not least because of the informal, behind the scenes manner in which the coalition works, there are a number of processes that observers suggest GGLC has contributed to, even if the precise nature of that contribution is sometimes hard to define.

At the local level GGLC's support to the development of the Ha'apai Green Growth Strategy in Tonga-and its subsequent integration into the Ha'apai Development Master Plan, provides a concrete example of GGLC's contribution to a provincial level process. This involved both technical assistance and political support to the Civil Society Forum of Tonga and the Tonga National Leadership Development Forum. The Ha'apai Green Growth Strategy began with community consultations across the province of Ha'apai. These were then shaped into "a document which provided guidance for environmentally friendly economic growth that promoted local customs and livelihoods" (Craney \& Hudson, 2020, p. 7). This in turn led to the Ha'apai Development Committee supporting a declaration to integrate 'green growth' principles into Tongan national development plans. This included GGLC providing input to the Tonga National Dialogue on Green Growth in November 2016 which was hosted by the Tonga National Leadership Development Forum and was attended by the Deputy Prime Minister of Tonga (a member of GGLC), and the Crown Prince, Tupouto'a ‘Ulukalala (IUCN, 2016).

At the national scale in Vanuatu, GGLC is seen as having made an important contribution to the Vanuatu National Sustainable Development Plan, Vanuatu 2030: The Peoples Plan. Some observers have referred to it as "the pinnacle outcome of coalition influence to date" (Craney \& Hudson, 2020, p. 1659). Hon. Ralph Regenvanu, who was Minister of Lands and Natural Resources at the time and who was part of the GGLC coalition, played a key role (also assisted by Fei Tevi, another leading player in GGLC). The plan reflects GGLC's holistic understanding of development and is based on three foundational pillars of sustainable development: society, environment and economy (Government of Vanuatu, 2016, p. 1).
Some question the degree to which the work of the Department of Energy in Vanuatu, which has carriage of green growth, is aligned to this holistic picture (Dornan, Morgan, Cain, \& Tarte, 2018, p. 418); or whether its inclusion was more about accessing international climate financing (Dornan et al., 2018, p. 420). However, others see the Vanuatu 2030 plan as a major step forward. The IUCN, for instance, notes that the Vanuatu Business Review at the time of the plan's launch said "this time, due largely to the intercession of IUCN and the GGLC initiative, we were about to change the way we talked about development" (IUCN, 2017, p. 12).

Finally, at a regional level, GGLC is seen as contributing to the deepening of the narratives of green growth and the blue-green economy in the Pacific. Dornan and his co-authors suggest that "[a]mong the regionally focused groupings advocating for green growth, the Green Growth Leaders Coalition has been particularly significant" (Dornan et al., 2018, p. 415). They note how GGLC linked the concepts of environmental sustainability and resilience with notions of social relationships and indigenous culture in ways that vernacularised discourses that were often used, or defined differently, elsewhere. The burgeoning use of the terms 'green growth' and 'blue-green economy,' linked in turn to notions of Pacific islands as "large ocean states" (Chan, 2018), is seen by some as part of a new assertive Pacific regionalism (Fry \& Tarte, 2018, p. 3) that is a significant departure from donor-dominated agendas of the past.

This case might be seen to represent a superficial attempt to shift aspirational national or regional policies and strategies that lack the resources and capacity for implementation. However, we argue that the GGLC was highly strategic and effective in reclaiming a Pacific centred narrative and developing, promoting and sharing a set of ideas that contest donor-led concepts of development and reticence to take meaningful action on climate change.

\section{Characteristics of Locally Led Development in the Pacific}

In examining Pacific case studies of locally led development, our intention is not to reassemble a reified culturally predetermined 'Pacific Way' or 'Melanesian Way,' even though these cultural narratives of tradition and modernity retain considerable currency and can be powerful mobilisers of social movements across the region (Titifanue, Kant, \& Finau, 2020). Nor do we seek to romanticise a spatially bounded idea of self-contained local actors who are innocently detached from the global. Rather, we observe a highly dynamic and fluid situation where 'local' leaders can make connections beyond their own immediate communities by investing in scalemaking projects that selectively reinvigorate old ways of doing things, reconfigure political dilemmas and bring in new ideas, options and resources. These rearticulations of the local at different scales are not restricted to 'devel- 
opmental leaders' with progressive intentions: Predatory elites can also mobilise the local, the national or the regional (or the connections between these scales) in ways that promote their narrow interests, and use their local identity in ways that reinforce inequality and injustice, and undermine developmental outcomes.

\subsection{Reclaiming Pacific World Views and Narratives}

Our cases provide examples of how local leaders have repurposed older Pacific traditions and narratives, including Christian themes. Sometimes this is found in the relatively holistic understandings of development and change where economic, social, environmental and spiritual goals are integrated and represent the shared patrimony of the groups in question. For example, in the case of the GGLC, deploying Hau'ofa's (1994) influential articulation of the deep cultural and environmental dimensions of Pacific islanders' ties to the ocean was crucial to building a cohesive trans-regional group identity. On Simbo, linking livelihoods, gender inequality, family safety and related social concerns to Christian faith and traditional leadership revitalised a collective island-wide identity (Suti et al., 2020). TVI drew on practices of Christian faith and personal awakening as the platform for constructing a new generation of leaders who can reclaim the promise of Papua New Guinea's constitutional vision of an egalitarian and prosperous nation. All resisted or reworked what Greg Fry has called, in reference to the Pacific region, "imposed framings" (Fry, 2019, p. 315) and reframed their own objectives and activities within existing scale-making projects (Pacific regionalism, Simbo as an island or TVI's reimagining of national leadership).

The groups in our case studies strategically deployed understandings of the local and mobilised collective identities at different scales to further common interests or goals. These Pacific collective identities are often at odds with the western modes of thought and practice prevalent in international development contexts: For example, where humanity (or the economy) is seen as separate from the environment; where formal process, public debate and contestation are more valued than less formal processes of consensus building and dialogue; and where faith, family and friendships are thought of as operating in spheres outside of professional life.

The day to day operations in each of the cases were characterised by the establishment of safe spaces for informal exchange and dialogue. This sometimes explicitly used indigenous forms of facilitating conversation like talanoa (Vaioleti, 2006) in the case of GGLC, or simply worked within the informal norms and structures of local clans (as in the Simbo case). These dialogical methods also demonstrate the importance of personal friendships and the recognition of interaction both during and outside of meetings or sessions (e.g., through eating and drinking together as a means of deepening mutual understanding, friendship and trust). Esther Suti's trans-Pacific, faith-based friendship with Adimaimalaga Tafunai, the friendship of the students that initiated TVI, and the "fellowship of like-minded individuals" who established GGLC are all important in understanding their success. As Ceridwen Spark has noted in her work on coalitions, friendships can be important not only for success but also for building the trust necessary in enduring hardship and challenges (Spark \& Lee, 2018, p. 1).

\subsection{Elites, the Pacific and Social Change}

The leaders in each case can be considered elite and indeed the term 'elite' is now a popular label for the educated classes of the Pacific (Cox, 2018, pp. 16-18; Gibson, 2019). GGLC was a self-appointed elite of influential Pacific public servants and community sector leaders (see Craney, 2020). TVI's membership reflects its middleclass student origins. Esther Suti, the principal catalyst of Simbo for Change, was a middle-class businesswoman based in the provincial capital.

Class and other privileges are part and parcel of political leadership in the Pacific and elsewhere (Corbett \& Wood, 2013; Spark, Cox, \& Corbett, 2019) and leaders from elite backgrounds are routinely criticised as being unrepresentative of broader populations. Here we do not claim that elites are representative, but our case studies do indicate that elite actors are able to mobilise movements that have inclusive, collective aims (see also Rousseau, 2012). Across the Pacific there are authoritarian, extractive or 'predatory' elites who rely on intimidation and male-dominated patronage politics (Cox, 2009; Wood, 2018). However, in most countries, the relative privilege of the middle classes is yet to evolve into a settled package of political demands or economic interests supportive of a stable political order (Barbara, Cox, \& Leach, 2015).

There are certainly trans-regional 'bottom up' movements that articulate progressive (largely urban middleclass) values on nuclear testing (George, 2011), climate change (Titifanue, Kant, Finau, \& Tarai, 2017) or West Papuan independence (Titifanue, Tarai, Kant, \& Finau, 2016; Webb-Gannon \& Webb, 2019). These movements all began in small, elite circles with strong connections to activists from outside the Pacific region but their ideas have spread well beyond the specific campaigns, NGOs or other institutions that promote them. Indeed, these causes have become part of a regional identity, mediated by social media (Titifanue et al., 2020) in ways that often leave Pacific governments out of step with the values of their citizens (Finau et al., 2014).

We see these dynamics as a similar process to Charles Taylor's (2004) description of the diffusion of the modern social imaginary from elite circles into broader society. This is not a matter of simple distribution but a practice of vernacularisation (Merry, 2006), where new concepts of society are rearticulated in local idioms. Each of our case studies provides a specific example of local elites leading a rearticulation of ideas of development that were initially introduced (or imposed) by colonial pow- 
ers, missionaries or aid agencies but that have since been "remixed" (Teaiwa, 2014) in ways that reflect local conditions and agendas at different scales.

\subsection{Collective Leadership, Relational Deliberation and Politics}

Individual well-being, rights and freedoms sit at the heart of much international development theory and practice. Yet these universalistic liberal approaches are not easily translated into local vernaculars (Merry, 2006) and may have unintended effects of side-lining or undermining local practice, world views and leadership styles that are more relational and collective. For example, as Ceridwen Spark (2020) has observed, donor rhetoric on rights and inclusion can be experienced as discrimination by Pacific women working in development programs. In Pacific cultures, cooperation, the maintenance of good relationships, and collective deliberation are highly valued, even if that can make processes seem slower, indecisive or ineffective to outsiders. These ways of working can also favour strengths-based approaches, which start with the mobilisation of internal resources to address locally determined problems, allowing existing skills and practices to be revalued and extended. Nevertheless, in some places, dependency on outside assistance and aid programs can undermine this resilience and local ownership (Yates, 2019). Processes of collective deliberation can be co-opted by the powerful for their own ends; or be so under-appreciated by expatriate program managers and funders that local actors give up in frustration (Spark, 2020).

The case studies also point to the importance of personal, community and political connections and networks, rather than representatives of civil society organisations, interest groups or 'stakeholders' in driving these initiatives. Furthermore, individuals often also wear many hats (e.g., government employee, church leader and NGO member with a small business practice-all at the same time). Relational ways of working seem to lead to a high degree of behind the scenes leadership and networking. In this way, the actors in the three case studies sought to complement and shape other institutions (e.g., regional bodies, national governments, churches, universities and traditional leadership), rather than seeking to undermine or replace them. In the case of Simbo for Change, this led to what might be described as a "quiet feminism" (Spark et al., 2019), which re-presented women's empowerment as an essential part of creating a cohesive island identity while restoring male chiefly prestige (Suti et al., 2020, p. 7). In the case of TVI, this involved the creation of what might be called 'women friendly spaces,' as well as reaching out to private sector companies that offered opportunities for young women leaders. For GGLC, working with relational cultural norms meant maintaining its informal status and engaging with existing heads of government, regional organisations and civil society leaders.

\subsection{External Support}

None of these initiatives were project-based, in that they did not start as projects with specific objectives, timelines and budgets, rather they evolved as processes of ongoing change that sought to address particular issues. All were founded upon: the promotion of shifts in ideas, beliefs and practices through largely informal processes; the creation of safe spaces for reflection, dialogue and debate; and doing so whilst maintaining and deepening respectful relationships.

On occasion, this led to resistance to-and sometimes refusal to engage with-standardised forms of development practice, project management, and donor branding that were felt to be detrimental or distracting. TVI refused Australian aid for additional program activities but put forward a successful counter proposal that provided resources for organisational reorientation. This has ultimately given the movement more autonomy and less dependence on a donor. GGLC did not compromise its messages on green growth, despite opposition to it from DFAT officials concerned about Australia's reputation on climate action. Esther Suti promoted a collective 'whole of island' approach rather than the more limited pilot initially preferred by technical advisors.

These tensions notwithstanding, each of the case study processes were relatively well supported in sensitive and small ways by external agencies (PLP in the cases of GGLC and Simbo; and Bread for the World with TVI). Despite general rhetorical commitments to supporting locally led change amongst aid agencies, in reality effective practice in this area is actually quite rare. This gap is due to a number of well-rehearsed reasons related to the political economy of the aid sector (see Roche \& Denney, 2019; Yanguas, 2018), and the tendency for organisational practices to endure despite their limitations (Fushimi, 2018). The case studies all represent, in different ways, a reversal in and resistance to the normal power relations between donor and local agency, because they were centrally driven by intrinsic (rather than extrinsic) motivations, dynamics and incentives.

Interestingly, both the Simbo and GGLC initiatives, despite their different scales, also illustrate the importance of intra-Pacific support, which can be more relevant and culturally appropriate, but which also has the ability to contest narrow thinking or expand ideas and connections. Under the PLP, experienced and highly skilled Pacific Islander staff played important intermediary roles, often as critical 'sounding boards' who introduced new ideas, questioned politically naive proposals or debated alternative courses of action. These external staff were also important in enabling broader connections nationally or regionally, and in playing a role of a trusted 'insider-outsider' who can be used to raise unwelcome issues without damaging the close relationships that local leaders are embedded in. These insider-outsiders often gave permission to 'local' actors to be more ambitious in their goals and more innova- 
tive in their practice of bringing others along a path of change.

\section{Conclusions}

This article adds to the literature on locally led development in three ways. First, it explores initiatives that were not established as projects by development agencies. Second, it takes a critical look at 'the local' and seeks to enrich understandings of the different ways in which local identities can be understood and, indeed, used to further particular interests. And third, we have sought to tease out what these types of initiatives might tell us about the characteristics of Pacific led development: characteristics that are often at odds with how conventional international development agencies tend to work, and that arguably provide those agencies with much food for thought.

Much of what we describe above is also consistent with postdevelopment conceptualisations of social change in which local, pluralist and solidaristic initiatives are central, and where connections to place, local knowledge and the non-human are highly valued. This of course begs the question as to what might be done to further promote and support such ways of working, particularly if they run counter to orthodox development practice. We offer three ideas as a contribution to the debate. Firstly, we suggest that further exploration of other 'indigenous' processes of locally led change in the Pacific might be instructive and help to build a broader and deeper repository of knowledge. Secondly, these case studies and findings might be socialised in ways that start to inform other Pacific networks working on linked issues such as The Pacific Community's SPC monitoring and evaluation network, who have just produced a key report on applying Pacific approaches to evidence gathering (Pacific Community, 2020), the Pacific Islands Association of Non-governmental Organisations and the Pacific Conference of Churches. Thirdly, these networks and a broader coalition of activists and sympathetic supporters could start to develop some principles and 'benchmarks' that might provide Pacific citizens and organisations with a means to hold their governments and international agencies to account.

The Covid-19 pandemic arguably provides a critical juncture (Tyrrel, Kelly, Roche, \& Jackson, 2020), or "a portal, a gateway between one world and the next" (Roy, 2020). In such moments, the structural drivers of behaviour are "significantly relaxed for a relatively short period" (Capoccia \& Kelemen, 2007, p. 343). In the current moment, there is an important opportunity to be debating both the nature of development and change in the Pacific, and in particular who is in the driving seat.

\section{Acknowledgments}

The authors are thankful to Fiame Naomi Mata'afa, Emeline Siale Ilolahia, Tuiloma Sina Retzlaff, Cathryn Buis,
Serena Sumanop, Barbra Thomas, Maliwai Sasingian, Wilson Toa, Allan Illingworth, Linda Kelly, Jope Tarai, Romitesh Kant, Ali Tuhanuku, Sivia Qoro, 'Ungatea Fonua Kata, Alfred Schuster, Jennifer Kalpokas, Jason Titifanue, Esther Suti, Lesley Hoatson, Adimaimalaga Tafunai, Fremden Yanhambath, May Garae, Joseph Zane Sikulu, Deborah Rhodes, Ceridwen Spark, Lisa Denney, Aiden Craney, and Kayli Wild all of whom contributed in one way or another to this article, as well as the four anonymous reviewers who provided us with rich feedback.

\section{Conflict of Interests}

The authors declare no conflict of interests.

\section{References}

Akwai, L. (2019, July 26). Honey can be a major source of income here. Solomon Star. Retrieved from https://www.solomonstarnews.com/index.php/ news/national/item/21748-honey-can-be-a-majorsource-of-income-here

Allen, M. G., \& Dinnen, S. (2015). Solomon Islands in transition? The Journal of Pacific History, 50(4), 381-397.

Barbara, J. (2019). Thinking and working politically in the Vanuatu skills sector: Supporting local leadership and building a political constituency for change. Canberra: Vanuatu Skills Partnership.

Barbara, J., Cox, J., \& Leach, M. (2015). The emergent middle classes in Timor-Leste and Melanesia: Conceptual issues and developmental significance (State, Society and Governance in Melanesia Discussion Paper No. 2015/4). Canberra: Australian National University.

Booth, D., \& Chambers, V. (2014). The SAVI Programme in Nigeria: Towards politically smart, locally led development (Discussion Paper). London: Overseas Development Institute.

Booth, D., \& Unsworth, S. (2014). Politically smart, locally led development (Discussion Paper). London: Overseas Development Institute.

Capoccia, G., \& Kelemen, D. (2007). The study of critical junctures: Theory, narrative and counterfactuals in historical institutionalism. World Politics, 59(3), 341-369.

Chan, N. (2018). Large ocean states: Sovereignty, small islands, and marine protected areas in global oceans governance. Global Governance: A Review of Multilateralism and International Organizations, 24(4), 537-555.

Christie, A., \& Green, D. (2018). Adaptive programming in fragile, conflict and violence-affected settings, what works and under what conditions? The case of Pyoe Pin, Myanmar (Discussion Paper). Brighton: ITAD and Oxfam in association with the Institute for Development Studies. Retrieved from https://opendocs. ids.ac.uk/opendocs/handle/20.500.12413/13888 
Corbett, J., \& Wood, T. (2013). Profiling politicians in Solomon Islands: Professionalisation of a political elite? Australian Journal of Political Science, 48(3), 320-334.

Cox, J. (2009). Active citizenship or passive clientelism? Accountability and development in Solomon Islands. Development in Practice, 19(8), 964-980.

Cox, J. (2017). Kindy and grassroots gender transformations in Solomon Islands. In M. Macintyre \& C. Spark (Eds.), Transformations of gender in Melanesia (pp. 69-94). Canberra: ANU Press.

Cox, J. (2018). Fast money schemes: Hope and deception in Papua New Guinea. Bloomington, IN: Indiana University Press.

Craney, A. (2020). Local participation or elite capture in sheep's clothing? A conundrum of locally led development. Politics and Governance, 8(4), 191-200.

Craney, A., \& Hudson, D. (2020). Navigating the dilemmas of politically smart, locally led development: The Pacific-based Green Growth Leaders' Coalition. Third World Quarterly, 41(10), 1653-1669.

Denney, L., \& McLaren, R. (2016). Thinking and working politically to support developmental leadership and coalitions: The Pacific Leadership Program (DLP Research Paper No. 40). Birmingham: Developmental Leadership Program.

Dornan, M., Morgan, W., Cain, T. N., \& Tarte, S. (2018). What's in a term? 'Green growth' and the 'blue-green economy' in the Pacific islands. Asia and the Pacific Policy Studies, 5(3), 408-425.

Dureau, C. (2001). Recounting and remembering 'First Contact' on Simbo. In J. Mageo (Ed.), Cultural memory: Reconfiguring history and identity in the postcolonial Pacific (pp. 130-162). Honolulu, HI: University of Hawai'i Press.

Escobar, A. (2018). Designs for the pluriverse: Radical interdependence, autonomy, and the making of worlds. Durham, NC: Duke University Press.

Finau, G., Prasad, A., Kant, R., Tarai, J., Logan, S., \& Cox, J. (2014). Social media and e-democracy in Fiji, Solomon Islands and Vanuatu. In Proceedings of the twentieth Americas conference on information systems (pp. 3929-3937). Atlanta, GA: Association for Information Systems.

Fry, G. (2019). Framing the islands: Power and diplomatic agency in Pacific regionalism. Canberra: ANU Press.

Fry, G., \& Tarte, S. (2018). The 'new Pacific diplomacy': An introduction. In G. Fry \& S. Tarte (Eds.), The new Pacific diplomacy (pp. 3-19). Canberra: ANU Press.

Fushimi, K. (2018). The puzzle of the universal utilization of the logical framework approach: An explanation using the sociological new institutional perspective (Literature Review No. 14). Tokyo: JICA Research Institute.

George, N. (2011). Pacific women building peace: A regional perspective. The Contemporary Pacific, 23(1), 37-71.

Gibson, L. (2019). Class, labour and consumption in urban Melanesia. In E. Hirsch \& W. Rollason (Eds.), The Melanesian world (pp. 164-179). London: Routledge.

Government of Vanuatu. (2016). Vanuatu 2030: The people's plan. Port Vila: Department of Strategic Policy, Planning and Aid Coordination.

Hau'ofa, E. (1994). Our sea of islands. The Contemporary Pacific, 6(1), 147-161.

International Fund for Agricultural Development. (2018). Women lead a revived honey industry in the Solomon Islands. International Fund for Agricultural Development. Retrieved from https://www.ifad.org/en/ web/latest/story/asset/40807922

International Union for Conservation of Nature. (2016). Pacific leaders meet to share and inspire. International Union for Conservation of Nature. Retrieved from https://www.iucn.org/content/pacific-leadersmeet-share-and-inspire

International Union for Conservation of Nature. (2017). IUCN in Oceania 2016 annual report. Suva: International Union for Conservation of Nature Oceania Field Office.

Klein, E., \& Morreo, C. E. (Eds.). (2019). Postdevelopment as practice: Alternatives, economies, ontologies. London: Routledge.

Lauer, M., Albert, S., Aswani, S., Halpern, B. S., Campanella, L., \& La Rose, D. (2013). Globalization, Pacific Islands, and the paradox of resilience. Global Environmental Change, 23(1), 40-50.

Mac Ginty, R. (2015). Where is the local? Critical localism and peacebuilding, Third World Quarterly, 36(5), 840-856.

McCulloch, N., \& Piron, L.-H., (2019). Thinking and working politically: Learning from practice. Overview to Special Issue. Development Policy Review, 37(S1), 01-015.

McDougall, D. (2014). 'Tired for nothing': Women, chiefs, and the domestication of customary authority in Solomon Islands. In H. Choi \& M. Jolly (Eds.), Divine domesticities: Christian paradoxes in Asia and the Pacific (pp. 99-224). Canberra: ANU Press.

Merry, S. E. (2006). Transnational human rights and local activism: Mapping the middle. American Anthropologist, 108(1), 38-51.

Pacific Community. (2020). Pacific monitoring, evaluation and learning capacity strengthening rebbilib. Suva: Pacific Community.

Roche, C., \& Denney, L. (2019). How can developmental leadership be supported? (Developmental Leadership Program Foundational Paper No. 4). Birmingham: University of Birmingham.

Roepstorff, K. (2020). A call for critical reflection on the localisation agenda in humanitarian action. Third World Quarterly, 41(2), 284-301.

Rousseau, B. (2012). 'Vot long stret man': Personality, policy, and the election of Ralph Regenvanu, Vanuatu 2008. The Contemporary Pacific, 24(1), 98-118.

Roy, A. (2020, April 4). The pandemic is a portal. Financial 
Times. Retrieved from https://www.ft.com/content/ 10d8f5e8-74eb-11ea-95fe-fcd274e920ca

Sanga, K., \& Reynolds, M. (2018). Melanesian tok stori in leadership development: Ontological and relational implications for donor-funded programmes in the Western Pacific. International Education Journal, 17(4), 11-26.

Sidel, J., \& Faustino, J. (2020). Thinking and working politically in development: Coalitions for change in the Philippines. Pasig City: The Asia Foundation.

Spark, C. (2020). 'Two different worlds': Papua New Guinean women working in development in Port Moresby. Asia Pacific Viewpoint. Advance online publication. https://doi.org/10.1111/apv.12271

Spark, C., Cox, J., \& Corbett, J. (2019). Gender, political representation and symbolic capital: How some women politicians succeed. Third World Quarterly, 40(7), 1227-1245.

Spark, C., \& Lee, J. (2018). Successful women's coalitions in Papua New Guinea and Malaysia: Feminism, friendships and social change (DLP Research Paper No. 50). Birmingham: Developmental Leadership Program.

Suti, E., Hoatson, L., Tafunai, A., \& Cox, J. (2020). Livelihoods, leadership, linkages and locality: The Simbo for Change project. Asia Pacific Viewpoint. Advance online publication. https://doi.org/ 10.1111/apv.12260

Taylor, C. (2004). Modern social imaginaries. Durham, NC: Duke University Press.

Teaiwa, K. (2014). Culture moves? The Festival of Pacific Arts and dance remix in Oceania. Dance Research Aotearoa, 2, 2-19.

Titifanue, J., Kant, R., \& Finau, G. (2020). A crucible for bottom-up regionalism? The digital renaissance. Pacific Journalism Review: Te Koakoa, 26(1), 140-147.

Titifanue, J., Kant, R., Finau, G., \& Tarai, J. (2017). Climate change advocacy in the Pacific: The role of information and communication technologies. Pacific Jour- nalism Review: Te Koakoa, 23(1), 133-149.

Titifanue, J., Tarai, J., Kant, R., \& Finau, G. (2016). From social networking to activism: The role of social media in the Free West Papua campaign. Pacific Studies, 39(3), 255-280.

Tsing, A. (2000). The global situation. Cultural Anthropology, 15(3), 327-360.

Tsing, A. (2005). Friction: An ethnography of global connections. Princeton, NJ, and Oxford: Princeton University Press.

Tyrrel, L., Kelly, L., Roche, C., \& Jackson, E. (2020). Uncertainty and Covid-19: A turning point for monitoring, evaluation, research and learning? A discussion note for aid actors, policymakers and practitioners (Governance and Development Working Paper No. 7). Canberra and Bundoora: AbT Associates and La Trobe University.

Vaioleti, T. M. (2006). Talanoa research methodology: A developing position on Pacific research. Waikato Journal of Education, 12(1), 21-34.

van Voorst, R. (2019). Praxis and paradigms of local and expatriate workers in 'Aidland.' Third World Quarterly, 40(12), 2111-2128.

Walton, G. W. (2018). Anti-corruption and its discontents: Local, national and international perspectives on corruption in Papua New Guinea. New York, NY: Routledge.

Webb-Gannon, C., \& Webb, M. (2019). 'More than a music, It's a movement': West Papua decolonization songs, social media, and the remixing of resistance. The Contemporary Pacific, 31(2), 309-343.

Wood, T. (2018). The clientelism trap in Solomon Islands and Papua New Guinea, and its impact on aid policy. Asia \& the Pacific Policy Studies, 5(3), 481-494.

Yanguas, P. (2018). Why we lie about aid: Development and the messy politics of change. London: Zed Books.

Yates, R. (2019). Dependency on Australian aid and the introduction of inclusive education initiatives in Kiribati. Asia Pacific Policy Studies, 7(1), 112-123.

\section{About the Authors}
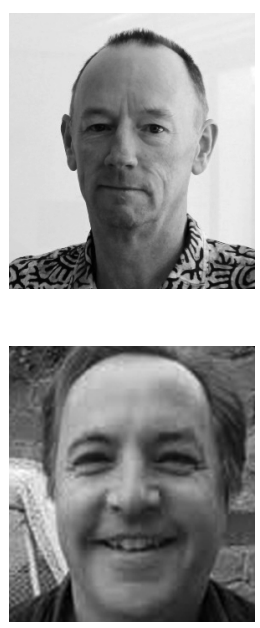

Chris Roche is Professor of Development Practice at La Trobe University, in Melbourne, Australia, and Director of the Institute for Human Security and Social Change. Chris is also Deputy Director (Impact) of the Developmental Leadership Program.

John Cox is a Social Anthropologist and Development Studies Specialist and an Honorary Associate of the Institute for Human Security and Social Change. 


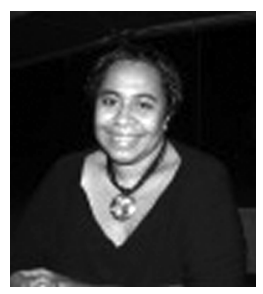

Mereani Rokotuibau is Team Leader of the Balance of Power Program, an initiative of Pacific Women Shaping Pacific Development, and is based in Suva, Fiji. Previously she worked as the Monitoring, Evaluation and Learning Unit Manager for the Solomon Islands Resource Facility, and for the Pacific Leadership Program.

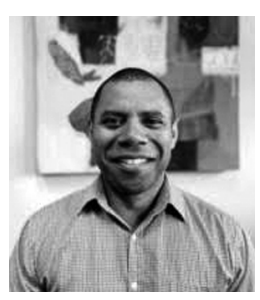

Peni Tawake is the Partnership and Coalition Manager at the Australia Pacific Training Coalition based in Suva, Fiji, and previously worked for the Pacific Leadership Program.

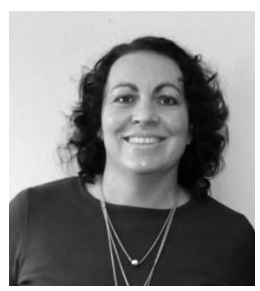

Yeshe Smith is Programs and Partnerships Manager at the Institute for Human Security and Social Change, and an Accredited Partnership Broker with the Partnership Brokers Association. 